\title{
Characterization of the synthetic cannabinoid MDMB-CHMCZCA
}

\author{
Carina Weber ${ }^{\ddagger 1}$, Stefan Pusch ${ }^{\ddagger 1}$, Dieter Schollmeyer ${ }^{1}$, Sascha Münster-Müller ${ }^{2}$, \\ Michael Pütz ${ }^{*}$ and Till Opatz*1
}

\author{
Full Research Paper \\ Address: \\ 1Johannes Gutenberg University Mainz, Institute of Organic \\ Chemistry, Duesbergweg 10-14, 55128 Mainz, Germany and \\ ${ }^{2}$ Bundeskriminalamt - Federal Criminal Police Office (BKA), Forensic \\ Science Institute, KT 45 - Toxicology, Äppelallee 45, 65203 \\ Wiesbaden, Germany \\ Email: \\ Michael Pütz - michael.puetz@bka.bund.de; Till Opatz - \\ opatz@uni-mainz.de \\ * Corresponding author $\ddagger$ Equal contributors \\ Keywords: \\ chiral HPLC; ECD spectroscopy; NPS; synthetic cannabinoids; VCD \\ spectroscopy \\ Beilstein J. Org. Chem. 2016, 12, 2808-2815. \\ doi:10.3762/bjoc. 12.279 \\ Received: 15 November 2016 \\ Accepted: 08 December 2016 \\ Published: 21 December 2016 \\ Associate Editor: I. R. Baxendale \\ (c) 2016 Weber et al.; licensee Beilstein-Institut. \\ License and terms: see end of document.
}

\begin{abstract}
The synthetic cannabinoid MDMB-CHMCZCA was characterized by various spectroscopic techniques including NMR spectroscopy and tandem mass spectrometry. The synthetic sample was found to be of $S$-configuration by VCD spectroscopy and comparison of the data with DFT calculations, while ECD spectroscopy was found to be inconclusive in this case. The enantiomeric purity of samples from test purchases and police seizures was assessed by a self-developed chiral HPLC method.
\end{abstract}

\section{Introduction}

Starting in 2008 with the appearance of "Spice products", herbal mixtures spiked with synthetic cannabinoid receptor agonists began to spread on the international drug market [1,2]. The cannabimimetic substances are the psychoactive ingredients of those mixtures and serve as a marijuana substitute with the intention to circumvent the narcotics regulations. Within the past years, the number of registered new psychoactive substances (NPS) has increased tremendously and currently lies around 600, 98 of which have only appeared in 2015 [3]. In response, the European authorities collaborate closely in terms of information exchange, risk assessment and control of NPS [4]. The first substance reported to the European Early Warning System (EWS) of the European Monitoring Centre for Drugs and Drug Addiction (EMCDDA) in this context was JWH-018 (1, Figure 1), originally developed for medical applications [5].

More recently, the synthetic $\mathrm{CB}_{1}$ receptor ligand MDMBCHMICA (2) attracted public and regulatory attention as several cases of severe intoxication and death were linked to this compound [6,7]. Up to November 2016, MDMB-CHMICA 
<smiles>CCCCCn1cc(C(=O)c2cccc3ccccc23)c2ccccc21</smiles><smiles>CCCCCn1c2ccccc2c2cc(C(=O)c3cccc4ccccc34)ccc21</smiles><smiles>COC(=O)C(NC(=O)c1cn(CC2CCCCC2)c2ccccc12)C(C)(C)C</smiles>

2

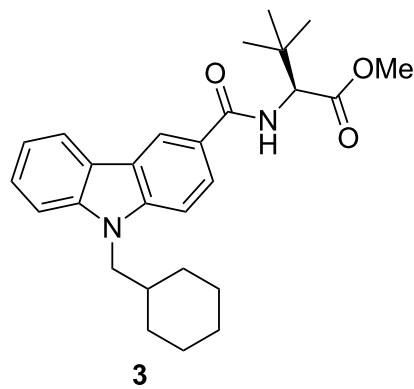

Figure 1: Synthetic cannabinoids JWH-018 (1), MDMB-CHMICA (2), MDMB-CHMCZCA (3), and EG-018 (4).

is controlled through legislation in 17 of the 30 member states of the EMCDDA [8]. It contains an $\mathrm{N}$-alkylated indole core structure with carboxamide substituent in C-3 position, linked to an tert-leucine methyl ester and in previous studies, the amino acid was shown to be $S$-configurated [9].

Lately, the new synthetic cannabinoid MDMB-CHMCZCA (3) was found on the drug market in the form of pure powder samples or as active substance in herbal mixtures ("Spice products"). Between October 7th, 2015 and October 19th, 2016, seven EU member states reported seizures or samples from test purchases in internet shops containing MDMB-CHMCZCA to the EWS of the EMCDDA. The first reported occurrence was a seizure by Swedish customs in September 2015 [10]. The structure of MDMB-CHMCZCA, a semi-systematic name for methyl dimethylbutanoatecyclohexylmethylcarbazolecarboxamide, is related to the structure of MDMB-CHMICA, but contains an $\mathrm{N}$-alkylated carbazole instead of an indole core. Carbazoles are the core structures of an emerging group of cannabimimetics [11,12]. Several $N$-alkylated carbazole-3-carboxamides were patented by Diaz, Diaz, and Petrov in 2012 as tricyclic cannabinoid receptor modulators, explored against neuropathic pain [13]. Nevertheless, only few carbazole derivatives have appeared as NPS on the drug market so far, one of which is EG-018 (4), the carbazole analogue to JWH-018 (1) [14,15]. Another example is EG-2201, the carbazole analoge to AM-2201, which is a derivative of JWH-018 with a 5-fluoro substitutent in the $N$-pentyl chain.
As part of the ongoing EU-project "SPICE profiling", MDMBCHMCZCA samples from test purchases in online shops and police seizures were analyzed to obtain analytical data and chemical properties. Another aim was to assess the absolute configuration and optical purity of the selected product samples. For this purpose, we used analytical methods such as NMR, tandem mass spectrometry, vibrational and electronic circular dichroism spectroscopy (VCD and ECD), as well as chiral HPLC.

\section{Results and Discussion}

Pure MDMB-CHMCZCA (3) was obtained as a so-called "research chemical" (RC) from an online RC shop (test purchase 1, December 2015), a colorless powder with the following analytical key data, supporting the structure from Figure 2.

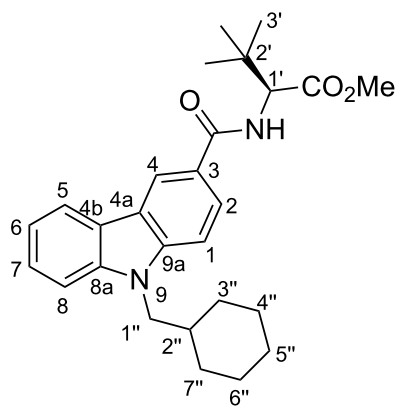

(S)-3

Figure 2: Molecular structure of (S)-MDMB-CHMCZCA (3) with numbering scheme.

Analytical properties of MDMB-CHMCZCA (methyl $N$ - $\{[9-$ (cyclohexylmethyl)-9H-carbazol-3-yl]carbonyl\}-3-methyl-Lvalinate). ${ }^{1} \mathrm{H} \mathrm{NMR}, \mathrm{COSY}, \mathrm{NOESY}\left(600 \mathrm{MHz}, \mathrm{CDCl}_{3}\right) \delta_{\mathrm{H}} /$ ppm 8.58 (d, $J=1.7 \mathrm{~Hz}, 1 \mathrm{H}, \mathrm{H}-4), 8.17-8.15$ (m, 1H, H-5), $7.92(\mathrm{dd}, J=8.6 \mathrm{~Hz}, 1.7 \mathrm{~Hz}, 1 \mathrm{H}, \mathrm{H}-2), 7.52-7.49$ (m, 1H, H-7), 7.44-7.42 (m, 1H, H-8), 7.30-7.28 (m, 1H, H-6), 6.77 (d, $J=$ $9.3 \mathrm{~Hz}, 1 \mathrm{H}, \mathrm{CON} H), 4.80$ (d, $\left.J=9.3 \mathrm{~Hz}, 1 \mathrm{H}, \mathrm{H}-1^{\prime}\right), 4.14$ (d, $J=$ $\left.7.4 \mathrm{~Hz}, 2 \mathrm{H}, \mathrm{H}_{2}-1 "\right), 3.78$ (s, 3H, OMe), 2.02-1.99 (m, 1H, H-2"), 1.72-1.64 (m, 5H, H-3a", H-4a", H-5a", H-6a", H-7a"), 1.18-1.10 (m, 5H, H-3b", H-4b", H-5b", H-6b", H-7b"), 1.10 (s, $\left.9 \mathrm{H}, \mathrm{C}\left(\mathrm{CH}_{3}\right)_{3}\right) ;{ }^{13} \mathrm{C} \mathrm{NMR}$, HSQC, HMBC $\left(151 \mathrm{MHz}, \mathrm{CDCl}_{3}\right)$ $\delta_{\mathrm{C}} / \mathrm{ppm} 172.7\left(\mathrm{CO}_{2} \mathrm{Me}\right), 167.9(\mathrm{CONH}), 143.0(\mathrm{C}-9 \mathrm{a}), 141.6$ (C-8a), 126.4 (C-7), 124.7 (C-2, C-3 overlapping), 122.8 (C-4b), 122.7 (C-4a), 120.8 (C-5), 120.1 (C-4), 119.7 (C-6), 109.6 (C-8), 109.9 (C-1), 60.4 (C-1'), $52.1\left(\mathrm{OCH}_{3}\right), 49.9$ (C-1"), 38.3 (C-2"), 35.4 (C-2'), 31.6 (C-3", C-7"), $26.9\left(\mathrm{C}\left(\mathrm{CH}_{3}\right)_{3}\right), 26.4$ (C-5"), 25.9 (C-4", C-6"); [ $\left.{ }^{1} \mathrm{H},{ }^{15} \mathrm{~N}\right]-\mathrm{HSQC},\left[{ }^{1} \mathrm{H},{ }^{15} \mathrm{~N}\right]-\mathrm{HMBC}$ $\left(600 \mathrm{MHz}, \mathrm{CDCl}_{3}\right) \delta_{\mathrm{N}} / \mathrm{ppm} 120.9(\mathrm{~N}-9), 106.3(\mathrm{CONH}) ; \mathrm{mp}$ 
171.5-172.4 ${ }^{\circ} \mathrm{C}$; ESIMS $m / z: 457.3\left(19.9 \%,[\mathrm{M}+\mathrm{Na}]^{+}\right), 435.4$ $\left(100 \%,[\mathrm{M}+\mathrm{H}]^{+}\right), 290.3$ (6.3\%, fragment); HRMS-ESI $\mathrm{m} / \mathrm{z}$ : calculated for $\left[\mathrm{C}_{27} \mathrm{H}_{35} \mathrm{~N}_{2} \mathrm{O}_{3}+\mathrm{H}\right]^{+}$, 435.2648; found, 435.2654; $[\alpha]_{\mathrm{D}}{ }^{25}+38.6^{\circ}\left(c 0.87, \mathrm{CDCl}_{3}\right)$.

A small impurity in the sample appears in the COSY experiment $\left(\delta_{\mathrm{H}}=3.09\right.$ and $1.40 \mathrm{ppm}$, see the Supporting Information File 1 for details). This is most probably a triethylammonium salt resulting from the use of triethylamine as a base during the preparation of the material. The ESI-MS ${ }^{n}$ fragmentation pathway of $\mathbf{3}$ is shown in Figure 3 and starts with cleavage of the amide, followed by loss of $\mathrm{CO}$ and/or a cyclohexyl radical or methylenecyclohexane.

As MDMB-CHMCZCA bears a stereogenic center at C-1', the elucidation of the absolute configuration of the sample was attempted by ECD spectroscopy. While the UV spectra can be adequately predicted by TD-DFT calculations (time-dependent density functional theory, see Supporting Information File 1 for details), a comparison of the experimental and calculated ECD spectra did not allow for a safe assignment of the cannabimimetic's absolute configuration (Figure 4).

The main two positive ECD signals in the range above $230 \mathrm{~nm}$ are correctly predicted by TD-DFT; however, the experimental positive/negative sequence is inverted in the range from 200 to $230 \mathrm{~nm}$. Overall, this yields an enantiomeric similarity index

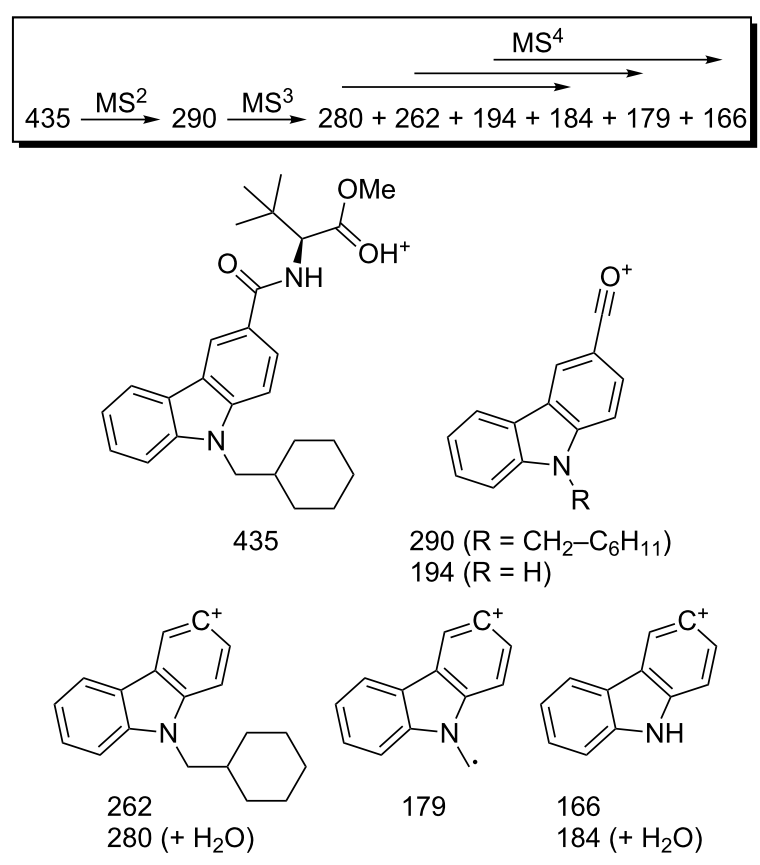

Figure 3: ESI-MS ${ }^{n}$ pattern of 3 ( $\mathrm{m} / \mathrm{z}$ values) with probable fragment ion structures.

(ESI) [16] of only $34 \%$ in favor of the $S$-enantiomer, therefore not enabling a reliable assignment of the absolute configuration. The theoretical predictions do not change significantly if the

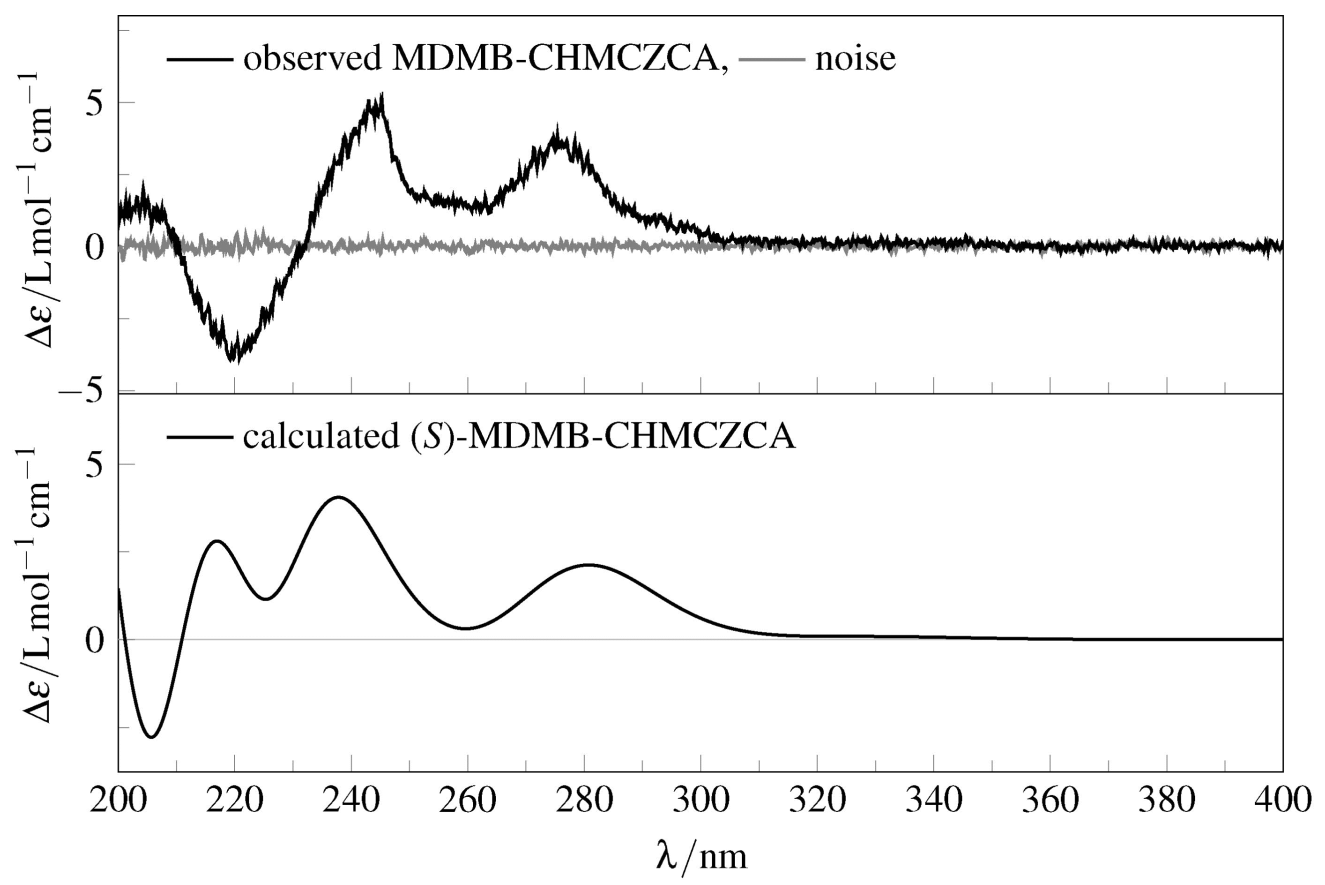

Figure 4: Observed (top) and calculated (bottom) ECD spectra for (S)-3 in acetonitrile, theory level: TD-B3LYP/6-311++G**/IEFPCM//B3PW91/6$311 \mathrm{G}^{* *} /$ IEFPCM. 
Tamm-Dancoff approximation (TDA) is used (see Supporting Information File 1 for details). The same holds true if Ahlrichs basis sets are used in place of the traditional Pople basis sets irrespective of different solvation models (COSMO or SMD) or the inclusion of diffuse functions (def2-TZVPP vs ma-def2TZVPP). The use of the range-separated (long-range corrected) CAM-B3LYP and $\omega$ B97XD functionals - probably more appropriate for the description of charge-transfer states - also did not lead to an improvement of the data.

On the other hand, an assignment was possible by comparison of the experimental and DFT-calculated VCD spectra (Figure 5) with a satisfactory ESI value of $80 \%$.

Eventually, the absolute configuration of $(S)$-3 could be unambiguously determined by X-ray structure analysis of a single crystal, which was obtained by slow cooling of a hot saturated solution of $(S)$-3 in cyclohexane (Figure 6, see also CCDC 1521512 for details).

To assess the enantiomeric purity of the material, racemization of a small sample of $(S)$-3 was attempted by treatment with sodium methoxide in methanol at $80{ }^{\circ} \mathrm{C}$ for $12 \mathrm{~h}$ under rigorous exclusion of moisture, yielding an $R / S$ mixture. The HPLC method already developed for the related cannabinoid MDMBCHMICA [9] could be extended to the separation of the enantiomers. The commercial sample from test purchase 1 was found to be enantiopure $(S)-3$ within the detection limits (Figure 7). Essentially the same applies to seven other samples (Table 1); small amounts of the $(R)$-enantiomer could only be detected in the case of test purchase 3 .

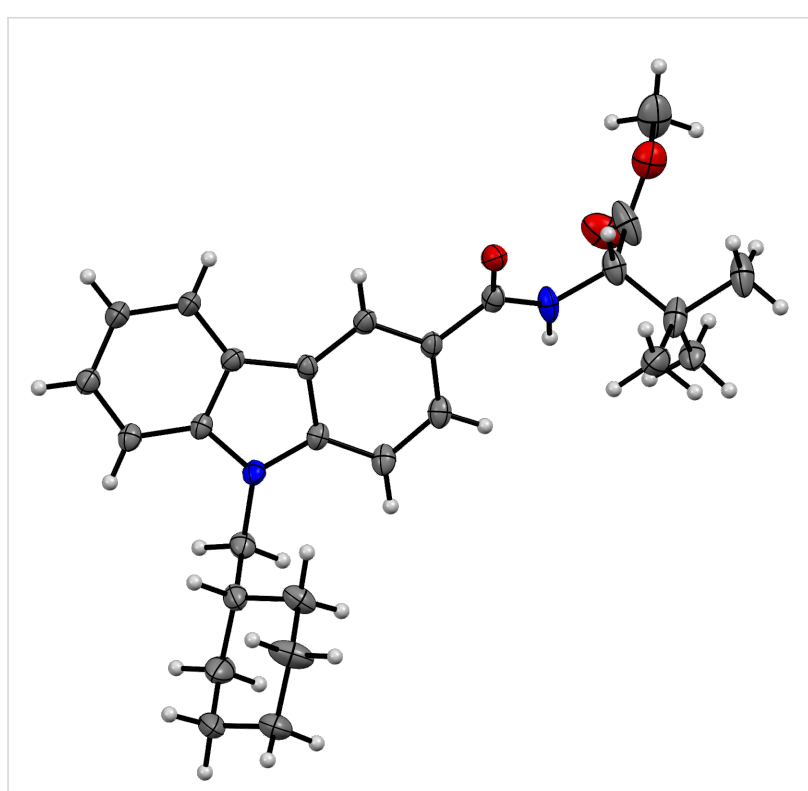

Figure 6: Molecular structure of (S)-3 in the solid state at $110 \mathrm{~K}$ (ORTEP-ellipsoids drawn at $30 \%$ probability, $\mathrm{C}$ black, $\mathrm{H}$ gray, $\mathrm{N}$ blue, O red).

\section{Conclusion}

A pure sample of the new synthetic cannabinoid MDMBCHMCZCA (3), purchased in an online RC shop, was characterized and the absolute configuration was determined to be $(S)$ by VCD spectroscopy and comparison with DFT calculations. Thus, the readily available $(S)$-tert-leucine would be a starting material for the synthesis of $(S)-3$. ECD spectroscopy was inferior to VCD in this case. The enantiomeric purity of material from five test purchases and three police seizures (pure

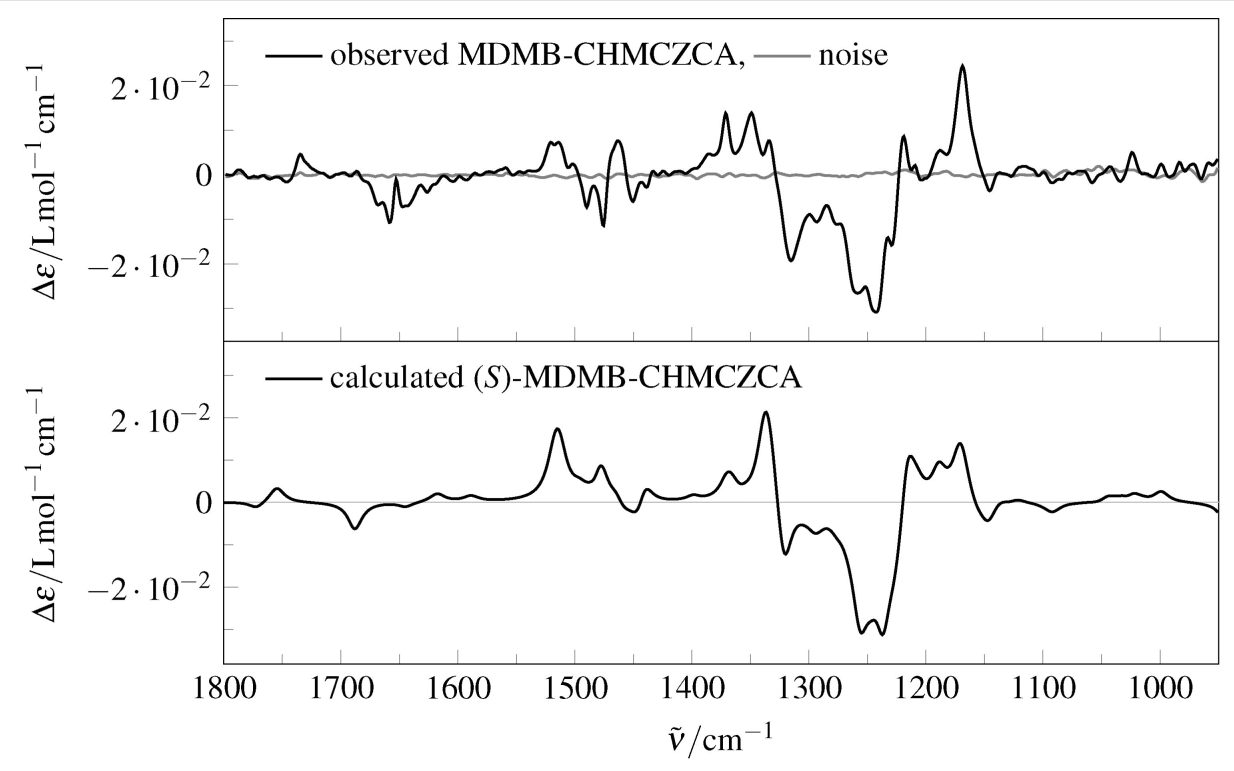

Figure 5: Observed (top) and calculated (bottom) VCD spectra for (S)-3 in chloroform, theory level: B3PW91/6-311G**/IEFPCM. 


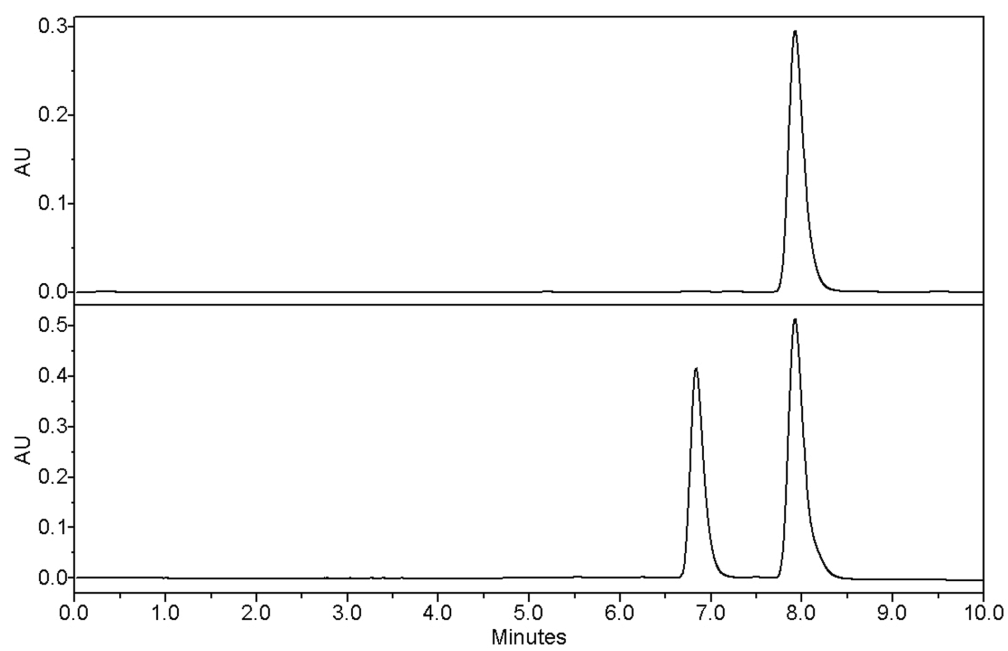

Figure 7: UV traces $\left(254 \mathrm{~nm}\right.$ ) of the chiral HPLC for commercial $(S)-3$ (top) and the $(R / S)-3$ (bottom). $t_{R}=6.84 \mathrm{~min}(R)$ and $7.93 \mathrm{~min}(S)$

\begin{tabular}{|c|c|}
\hline sample & ee \\
\hline$(R / S)-3$ & $18.5 \%$ \\
\hline test purchase $1(\operatorname{Dec} 2015)^{a}$ & $>99.0 \%$ \\
\hline test purchase 2 (May 2016) ${ }^{a}$ & $>99.0 \%$ \\
\hline test purchase 3 (Jan 2016) $^{b}$ & $97.0 \%$ \\
\hline test purchase 4 (Mar 2016) $^{\mathrm{C}}$ & $>99.0 \%$ \\
\hline test purchase $5\left(\right.$ Mar 2016) ${ }^{c}$ & $>99.0 \%$ \\
\hline police seizure 1 (Feb 2015) $^{\mathrm{C}}$ & $>99.0 \%$ \\
\hline police seizure $2($ Mar 2015) & $>99.0 \%$ \\
\hline police seizure $3(\text { Aug } 2016)^{C}$ & $>99.0 \%$ \\
\hline
\end{tabular}

substances as well as designer drug products) was assessed by chiral HPLC after base-induced racemization of a sample of $(S)-3$.

\section{Experimental Isolation of MDMB-CHMCZCA from Spice products}

In analogy to the procedure described in [9], hashish-like resin $(20 \mathrm{mg})$ was cut in small pieces, soaked in acetonitrile $(3 \mathrm{~mL})$ and sonicated for 20 minutes. The extract was filtered through a syringe filter $(0.45 \mu \mathrm{m})$ and dried under a steady stream of nitrogen, giving a colorless material. From each herbal blend sample (Spice product), plant material $(500 \mathrm{mg})$ was weighed and extracted twice with acetonitrile $(5 \mathrm{~mL}$ and $2 \mathrm{~mL})$. The extracts were combined, filtered through a syringe filter $(0.45 \mu \mathrm{m})$ and dried under a steady stream of nitrogen, giving a green material.
Further extract purification was achieved by preparative normal-phase chromatography with a Sepacore ${ }^{\circledR}$ flash system X50 (Büchi) consisting of two pump modules (max. 50 bar pressure), a UV-vis spectrometer (set to $285 \mathrm{~nm}$ ), an automated fraction collector and a control unit. A prepacked $4 \mathrm{~g}$ silica gel HP column (particle size 15-40 $\mu \mathrm{m}$, Büchi) was used. Separation was achieved using a gradient program of eluent A (hexane) and B (ethyl acetate) with a flow rate of $20 \mathrm{~mL} \mathrm{~min}^{-1}$, starting with $0 \% \mathrm{~B}$, increasing over 30 seconds to $10 \% \mathrm{~B}$. After 120 seconds, eluent $\mathrm{B}$ is further increased within 30 seconds to $30 \%$, which is held for 120 seconds. Lastly, eluent B is increased to $100 \%$ over 60 seconds and held for 240 seconds, giving an overall chromatographic runtime of 600 seconds. The fractions containing compound 3 were collected from 4 min to $4.6 \mathrm{~min}$ and subsequently evaporated to dryness.

\section{Nuclear magnetic resonance}

All nuclear magnetic resonance (NMR) data were acquired on an Avance-III $600 \mathrm{MHz}$ spectrometer (Bruker) with a $5 \mathrm{~mm}$ TCI CryoProbe. The ${ }^{1} \mathrm{H}$ and ${ }^{13} \mathrm{C}$ chemical shifts $(\delta)$ were referenced to the residual solvent signal as internal standard $\left(\delta_{\mathrm{H}}=\right.$ $7.26 \mathrm{ppm}$ and $\left.\delta_{\mathrm{C}}=77.16 \mathrm{ppm}\right)[17,18]$. The ${ }^{15} \mathrm{~N}$ chemical shifts were referenced to an external standard (nitromethane in DMSO- $\left.d_{6}, \delta_{\mathrm{N}}=380.2 \mathrm{ppm}\right)$ and the coupling constants $(J)$ are reported in $\mathrm{Hz}$.

\section{Melting point}

The melting point was determined in open capillary tubes with a KSP1N melting point meter (Krüss).

\section{HPLC/ESI-MS ${ }^{n}$}

HPLC/ESI-MS ${ }^{n}$ was performed on a 1200 series HPLC system with a UV diode array detector coupled with a LC/MSD trap 
XCT mass spectrometer (Agilent Technologies). Mixtures of acetonitrile and water (with $0.1 \%$ formic acid) were used as eluents at a total flow rate of $1.0 \mathrm{~mL} \mathrm{~min}^{-1}$ with the following gradient method: acetonitrile/water $(+0.1 \%$ formic acid $)=$ 10:90 (0-0.2 $\mathrm{min}), 10: 90$ to $90: 10$ (0.2-4.0 $\mathrm{min})$, and 90:10 (4.0-6.0 min). An Ascentis Express $\mathrm{C}_{18}$ column (length: $3 \mathrm{~cm}$, diameter: $2.1 \mathrm{~mm}$, particle size: $2.7 \mu \mathrm{m}$; Supelco) was used at a temperature of $40{ }^{\circ} \mathrm{C}$. The capillary voltage was set to $3500 \mathrm{~V}$ and the capillary exit voltage was set according to the respective target mass.

\section{High-resolution mass spectrometry}

High-resolution ESI mass spectrometry was performed on a Waters QTof Ultima 3 instrument (Waters) with a dual electrospray source and an external calibrant.

\section{Polarimetry}

The determination of the optical rotation was carried out at $589 \mathrm{~nm}$ and $25{ }^{\circ} \mathrm{C}$ in a Perkin-Elmer 241 polarimeter (Perkin Elmer) using a $10 \mathrm{~cm}$ path length quartz glass cuvette.

\section{Electronic spectroscopy}

UV and ECD spectra were obtained on a J-815 circular dichroism spectropolarimeter (Jasco) in a $1 \mathrm{~mm}$ (path length) quartz glass cuvette and a spectral range of 400-185 nm. The measurements were carried out with an acetonitrile solution of MDMBCHMCZCA $(0.25 \mathrm{mmol} / \mathrm{L})$, a scan speed of $20 \mathrm{~nm} / \mathrm{min}$ and 8 repetitions. The baseline was corrected by subtraction of a solvent spectrum recorded with the same parameters.

\section{Vibrational spectroscopy}

The infrared (IR) and vibrational circular dichroism (VCD) spectra were recorded with a Tensor 27 IR spectrometer (Bruker Optics) equipped with a PMA50 module for polarization modulation measurements. The photoelastic modulator was optimized for $1400 \mathrm{~cm}^{-1}$. The IR data were collected within 16 scans in a spectral range of $4000-800 \mathrm{~cm}^{-1}$. The measurement to obtain the VCD data was carried out with a solution of MDMB-CHMCZCA in $\mathrm{CDCl}_{3}(0.168 \mathrm{~mol} / \mathrm{L})$ in a $100 \mu \mathrm{m} \mathrm{BaF} 2$ sample cell with an accumulation time of $6 \mathrm{~h}$ (25,560 scans). The resolution in the spectral range of $1800-800 \mathrm{~cm}^{-1}$ was set to $4 \mathrm{~cm}^{-1}$. The IR and VCD spectra were baseline corrected by subtraction of a solvent spectrum recorded using the same measurement parameters.

\section{Computational methods}

Initially, 445 MMFF [19] and 470 PM6 [20] conformational candidates for $(S)$-3 were generated employing a sparse systematic search algorithm with Spartan'10 [21]. Both sets were combined, the candidates were optimized and vibrational frequencies were calculated with PM6 [20] using Gaussian 09,
Rev. D.01 [22]. Duplicates were removed based on comparison of the electronic energies and dipole moments as well as the free enthalpies and dipole moments, yielding 740 survivors. DFT reoptimization at the $\mathrm{B} 3 \mathrm{LYP} / 6-31 \mathrm{G}^{*}$ level [23-28] with IEFPCM (integral equation formalism polarizable continuum model) solvation [29] for chloroform, tight geometry convergence criteria, and an ultrafine integration grid yielded 619 conformers after removal of duplicates based on comparison of the electronic energies and dipole moments. The 242 conformers within a relative electronic energy range up to $10 \mathrm{kcal} / \mathrm{mol}$ were selected from this set. The geometries were reoptimized and vibrational frequencies were calculated at the B3LYP/6-311G** level [23-28] with IEFPCM solvation [29] for chloroform, tight geometry convergence criteria, and an ultrafine integration grid. Duplicates were removed based on comparison of the electronic energies and dipole moments as well as the free enthalpies and dipole moments (235 survivors). The 43 conformers within a relative electronic energy range up to $5 \mathrm{kcal} / \mathrm{mol}$ were selected from this set, the structures were confirmed as local minima (no imaginary frequencies), and enthalpy-Boltzmann-averaged IR and VCD spectra were generated. Using SpecDis 1.64 [16], the experimental and calculated IR spectra were fitted in the range from $950 \mathrm{~cm}^{-1}$ to $1550 \mathrm{~cm}^{-1}$ with screening values of $2 \mathrm{~cm}^{-1}$ to $10 \mathrm{~cm}^{-1}$ for the line broadening $\gamma$ as well as 0.9 to 1.1 for the scaling factor $s$. The experimental and calculated VCD spectra were then compared using these optimized parameters. The set of 242 conformers mentioned above was also subjected to a reoptimization and vibrational frequency calculation at the B3LYP/6-311G** level [23-28] with IEFPCM solvation [29] for acetonitrile, tight geometry convergence criteria, and an ultrafine integration grid using Gaussian 09, Rev. D.01 [22]. Duplicates were removed based on comparison of the electronic energies and dipole moments as well as the free enthalpies and dipole moments (234 survivors). The 46 conformers within a relative electronic energy range up to $5 \mathrm{kcal} / \mathrm{mol}$ were selected from this set, the structures were confirmed as local minima (no imaginary frequencies), and the geometries were used for the excited-state calculations. ECD spectra were calculated using TD-DFT (number of states: 75) at the TD- and TDA-B3LYP/6-311++G** [23-28,30] as well as the TD-CAM-B3LYP/def2-TZVPP [3133] and TD- $\omega B 97 X D /$ def2-TZVPP [32-35] levels with IEFPCM solvation [29] for acetonitrile and an ultrafine integration grid. ECD spectra were also calculated using TD-DFT (with TDA, number of roots: 100, size of the expansion space: 600) with Orca 3.0.3 [36] employing the B3LYP [23-26] or CAM-B3LYP [31] functionals, the def2-TZVPP basis set [32,33], the RIJCOSX approximation [37] together with the def2-TZVPP/J basis set, tight SCF criteria, enhanced grid settings (Grid5 FinalGrid6 GridX4) and COSMO solvation [38] for acetonitrile. Enthalpy-Boltzmann-averaged UV and ECD 
spectra were then generated in all cases. Using SpecDis 1.64 [16], the experimental and calculated UV spectra were fitted in the range from $200 \mathrm{~nm}$ to $400 \mathrm{~nm}$ using screening values of $0.1 \mathrm{eV}$ to $0.5 \mathrm{eV}$ for the line broadening $\sigma / \gamma$ as well as $-60 \mathrm{~nm}$ to $+60 \mathrm{~nm}$ for the shift value $s$; the experimental and calculated ECD spectra were then compared using these optimized parameters.

\section{Racemization}

Analogously as described in [9], $(S)-\mathbf{3}$ (2.5 mg) was added to a freshly prepared solution of sodium $(10 \mathrm{mg})$ in dry methanol $(3 \mathrm{~mL})$ under nitrogen and stirred at $80{ }^{\circ} \mathrm{C}$ for $12 \mathrm{~h}$. The mixture was quenched by addition of acetic acid $(2 \mathrm{~mL})$. Water $(30 \mathrm{~mL})$ was added and the mixture was extracted with ethyl acetate $(50 \mathrm{~mL})$. The organic layer was washed with saturated aqueous $\mathrm{NaHCO}_{3}(20 \mathrm{~mL})$ and brine $(20 \mathrm{~mL})$, and dried over sodium sulfate. The solvent was removed in vacuo to afford $(R / S)$-3 as a colorless solid $(2.3 \mathrm{mg}, 92 \%)$.

\section{Chiral HPLC}

Chiral HPLC was performed on an Alliance 2695 HPLC (Waters) coupled to a 996 PDA detector (Waters). Mixtures of hexane and 2-propanol were used as eluents at a total flow rate of $0.6 \mathrm{~mL} / \mathrm{min}$ with an isocratic ratio of hexane $/ 2$-propanol = 20:80. A Chiralpak IA-3 column (length: $25 \mathrm{~cm}$, diameter: $4.6 \mathrm{~mm}$, particle size: $3 \mu \mathrm{m}$; Daicel) was used at a temperature of $40{ }^{\circ} \mathrm{C}$.

\section{Supporting Information}

\section{Supporting Information File 1 \\ NMR spectra, UV and ECD spectra, IR and VCD spectra, HPLC/ESI-MS ${ }^{n}$, chiral HPLC, and computational chemistry. \\ [http://www.beilstein-journals.org/bjoc/content/ supplementary/1860-5397-12-279-S1.pdf]}

\section{Supporting Information File 2}

Chemical information file of compound $(S)-\mathbf{3}$. CCDC 1521512 contains the supplementary crystallographic data for this paper. The data can be obtained free of charge from The Cambridge Crystallographic Data Centre via http://www.ccdc.cam.ac.uk/structures [http://www.beilstein-journals.org/bjoc/content/ supplementary/1860-5397-12-279-S2.cif]

\section{Acknowledgements}

The authors thank Prof. Dr. Pol Besenius (Mainz) for granting access to the ECD spectrometer and the Zentrum für Datenver- arbeitung (Mainz) for access to the MOGON supercomputer. Financial support from the Naturstoffzentrum Rheinland-Pfalz is gratefully acknowledged. S. P. is grateful to the Fonds der chemischen Industrie for a Ph.D. fellowship. A part of this work was performed within the research project "SPICE-Profiling" (agreement no. JUST/2013/ISEC/DRUGS/AG/ISEC/ 4000006421) funded by the European Union's program " Fight Against and Prevention of Crime"' (ISEC). The contents of the paper are the sole responsibility of the authors and can in no way be taken to reflect the views of the European Commission.

\section{References}

1. Auwärter, V.; Dresen, S.; Weinmann, W.; Müller, M.; Pütz, M.; Ferreirós, N. J. Mass Spectrom. 2009, 44, 832-837. doi:10.1002/jms.1558

2. Uchiyama, N.; Kikura-Hanajiri, R.; Kawahara, N.; Haishima, Y.; Goda, Y. Chem. Pharm. Bull. 2009, 57, 439-441. doi:10.1248/cpb.57.439

3. EMCDDA-Europol 2015 Annual Report on the implementation of Council Decision 2005/387/JHA. http://www.emcdda.europa.eu/system/files/publications/2880/TDAS160 01ENN.pdf (accessed Nov 11, 2016).

4. Council Decision 2005/387/JHA of 10 May 2005 on the information exchange, risk-assessment and control of new psychoactive substances. http://eur-lex.europa.eu/eli/dec/2005/387/oj (accessed Nov 11, 2016).

5. Wiley, J. L.; Compton, D. R.; Dai, D.; Lainton, J. A. H.; Phillips, M.; Huffman, J. W.; Martin, B. R. J. Pharmacol. Exp. Ther. 1998, 285, 995-1004.

6. Franz, F.; Schwörer, N.; Angerer, V.; Moosmann, B.; Auwärter, V. Toxichem Krimtech 2015, 82, 192-198.

7. Langer, N.; Lindigkeit, R.; Schiebel, H.-M.; Papke, U.; Ernst, L.; Beuerle, T. Forensic Toxicol. 2016, 34, 94-107. doi:10.1007/s11419-015-0292-7

8. EMCDDA risk assessment report on a new psychoactive substance: methyl 2-[[1-(cyclohexylmethyl)-1H-indole-3-carbonyl]amino]-3,3-dimethylbuta noate (MDMB-CHMICA) (personal communication).

9. Andernach, L.; Pusch, S.; Weber, C.; Schollmeyer, D.; Münster-Müller, S.; Pütz, M.; Opatz, T. Forensic Toxicol. 2016, 34, 344-352. doi:10.1007/s11419-016-0321-1

10. EDND - European information system and database on new drugs. https://ednd-cma.emcdda.europa.eu (accessed Nov 1, 2016).

11. Petrov, R. R.; Knight, L.; Chen, S.-R.; Wager-Miller, J.; McDaniel, S. W.; Diaz, F.; Barth, F.; Pan, H.-L.; Mackie, K.; Cavasotto, C. N.; Diaz, P. Eur. J. Med. Chem. 2013, 69, 881-907. doi:10.1016/j.ejmech.2013.09.038

12. Bashir, M.; Bano, A.; ljaz, A. S.; Chaudhary, B. A. Molecules 2015, 20, 13496-13517. doi:10.3390/molecules200813496

13. Diaz, P.; Diaz, F.; Petrov, R. R. Novel Tricyclic Modulators of Cannabinoid Receptors. U.S. Pat. Appl. US 2012/0039804 A1, Feb 16 , 2012.

14. Schifano, F. Drugs Alcohol Today 2015, 15, 21-27. doi:10.1108/DAT-10-2014-0035

15. Hess, C.; Murach, J.; Krueger, L.; Scharrenbroch, L.; Unger, M.; Madea, B.; Sydow, K. Drug Test. Anal. 2016. doi:10.1002/dta.2030

16. Bruhn, T.; Schaumlöffel, A.; Hemberger, Y.; Bringmann, G. Chirality 2013, 25, 243-249. doi:10.1002/chir.22138 
17. Gottlieb, H. E.; Kotlyar, V.; Nudelman, A. J. Org. Chem. 1997, 62, 7512-7515. doi:10.1021/jo971176v

18. Fulmer, G. R.; Miller, A. J. M.; Sherden, N. H.; Gottlieb, H. E.; Nudelman, A.; Stoltz, B. M.; Bercaw, J. E.; Goldberg, K. I. Organometallics 2010, 29, 2176-2179. doi:10.1021/om100106e

19. Halgren, T. A. J. Comput. Chem. 1996, 17, 490-519. doi:10.1002/(SICI)1096-987X(199604)17:5/6<490::AID-JCC1>3.0.CO; 2-P

20. Stewart, J. J. P. J. Mol. Model. 2007, 13, 1173-1213. doi:10.1007/s00894-007-0233-4

21. Spartan'10; Wavefunction, Inc.: Irvine, CA, USA, 2009

22. Gaussian 09, Revision D.01; Gaussian, Inc.: Wallingford, CT, USA, 2009.

23. Vosko, S. H.; Wilk, L.; Nusair, M. Can. J. Phys. 1980, 58, 1200-1211. doi:10.1139/p80-159

24. Lee, C.; Yang, W.; Parr, R. G. Phys. Rev. B 1988, 37, 785-789. doi:10.1103/PhysRevB.37.785

25. Becke, A. D. J. Chem. Phys. 1993, 98, 5648-5652. doi:10.1063/1.464913

26. Stephens, P. J.; Devlin, F. J.; Chabalowski, C. F.; Frisch, M. J. J. Phys. Chem. 1994, 98, 11623-11627. doi:10.1021/j100096a001

27. Krishnan, R.; Binkley, J. S.; Seeger, R.; Pople, J. A. J. Chem. Phys. 1980, 72, 650-654. doi:10.1063/1.438955

28. Frisch, M. J.; Pople, J. A.; Binkley, J. S. J. Chem. Phys. 1984, 80, 3265-3269. doi:10.1063/1.447079

29. Tomasi, J.; Mennucci, B.; Cancès, E. J. Mol. Struct.: THEOCHEM 1999, 464, 211-226. doi:10.1016/S0166-1280(98)00553-3

30. Clark, T.; Chandrasekhar, J.; Spitznagel, G. W.; von Ragué Schleyer, P. J. Comput. Chem. 1983, 4, 294-301. doi:10.1002/jcc.540040303

31. Yanai, T.; Tew, D. P.; Handy, N. C. Chem. Phys. Lett. 2004, 393, 51-57. doi:10.1016/j.cplett.2004.06.011

32. Schäfer, A.; Horn, H.; Ahlrichs, R. J. Chem. Phys. 1992, 97, 2571-2577. doi:10.1063/1.463096

33. Weigend, F.; Ahlrichs, R. Phys. Chem. Chem. Phys. 2005, 7, 3297-3305. doi:10.1039/b508541a

34. Chai, J.-D.; Head-Gordon, M. Phys. Chem. Chem. Phys. 2008, 10, 6615-6620. doi:10.1039/b810189b

35. Chai, J.-D.; Head-Gordon, M. J. Chem. Phys. 2008, 128, 084106. doi:10.1063/1.2834918

36. Neese, F. Wiley Interdiscip. Rev.: Comput. Mol. Sci. 2012, 2, 73-78. doi:10.1002/wcms.81

37. Neese, F.; Wennmohs, F.; Hansen, A.; Becker, U. Chem. Phys. 2009, 356, 98-109. doi:10.1016/j.chemphys.2008.10.036

38. Klamt, A.; Schüürmann, G. J. Chem. Soc., Perkin Trans. 2 1993, 799-805. doi:10.1039/P29930000799

\section{License and Terms}

This is an Open Access article under the terms of the Creative Commons Attribution License

(http://creativecommons.org/licenses/by/4.0), which permits unrestricted use, distribution, and reproduction in any medium, provided the original work is properly cited.

The license is subject to the Beilstein Journal of Organic Chemistry terms and conditions:

(http://www.beilstein-journals.org/bjoc)

The definitive version of this article is the electronic one which can be found at:

doi:10.3762/bjoc. 12.279 